\title{
Hypolipidemic action of Rutin on Triton WR-1339-induced hyperlipidemia in rats
}

\author{
Livingston Raja NR ${ }^{1, A-F \oplus}$, Aathira Ravindran Nair ${ }^{1, A-B \oplus}$, Swarnabala Senthilpandian ${ }^{1, A-B \oplus \text {, }}$ \\ Vijay Ravi ${ }^{1, A-B}$ Ф \\ 1 S. A. Raja Pharmacy College, Rajas Nager, India \\ A - Research concept and design, B - Collection and/or assembly of data, C - Data analysis and interpretation, \\ $D$ - Writing the article, E - Critical revision of the article, F - Final approval of article
}

\begin{abstract}
Livingston Raja NR, Aathira Ravindran Nair, Swarnabala Senthilpandian, Vijay Ravi. Hypolipidemic action of Rutin on Triton WR-1339-induced hyperlipidemia in rats. J Pre-Clin Clin Res. 2021; 15(2): 51-55. doi: 10.26444/jpccr/136231
\end{abstract}

\section{Abstract}

Introduction and objective. Hyperlipidemia is considered as a serious communal problem in developed countries, caused by an excess level of cholesterol in blood circulation. It leads to chronic illness and even death in human beings. As the currently available drugs cause unexpected side-effect, the aim of this study is to concentrate on naturally occurring flavonoids which can potentially provide defensive and therapeutic effects in atherosclerosis diseases, and investigate the hypolipidemic effect of rutin on Triton WR-1339 triggered hyperlipidemia in a rat blood sample.

Materials and method. Rats were randomly prearranged into five different groups of five rats each. Group-I was the non-disease control and administered normal saline. Group-II was the atherogenic control, administered Triton WR 1339 (200 mg/kg BW). Group-III was standard and received Atorvastatin. The last two groups (IV, V) were tested (I\&II) by administering administered Rutin $(40 \mathrm{mg} / \mathrm{kg}, 80 \mathrm{mg} / \mathrm{kg})$ orally. The test material (I\&II) and the standard drug were administered for seven days. After the last dose, blood samples were collected and the lipid levels estimated in the blood samples.

Results. Rats treated with rutin flavonoid at a dose of $40 \mathrm{mg} / \mathrm{kg} \& 80 \mathrm{mg} / \mathrm{kg}$ exhibited a reduction in Total Cholesterol, Triglycerides, Low Density Lipoprotein (LDL) and Very Low Density Lipoprotein (VLDL). Rutin also increases the High Density Lipoprotein (HDL), compared with control rats. Rutin treated rats exhibited dose-dependent hypolipidemic activity. The protection percentage of rutin against hyperlipidemia was observed as $41.89 \%, 55.57 \%$ whereas the atorvastatin treated group protection was observed at $60.63 \%$.

Conclusions. The results of the study revealed that rutin showed a significant hypolipidemic effectiveness on Triton WR1339 induced hyperlipidemia in rats.

\section{Key words}

Rutin, Flavonoid, Triglycerides, Atorvastatin, Hypolipidemic, Triton WR-1339

\section{INTRODUCTION}

Hypercholestermia is a life-threatening disorder that develops through elevated lipids content in the blood circulation. Lipids play a vital role in the body's muscle growth, but an abnormal level of fats in the blood highly increases the risk factor for developing coronary heart diseases. Nowadays, cardiovascular diseases are a serious life-threatening epidemic disorder in India [1]. Cardiovascular diseases are responsible for one-third of the total deaths worldwide, and it is believed that cardiovascular diseases will prove to be a leading cause of morbidity and mortality in forthcoming years [2].

Hyperlipidemia is caused by the elevation of total cholesterol, triglycerides, very low density lipoprotein, and low density lipoprotein in plasma. Hyperlipidemia is also caused by a decreased level of high density lipoprotein in blood. Hyperlipidemia with an elevated level of lipoproteins is measured by the initiation and progression of plaque formation in arteries which may causes thrombosis and myocardial infraction [3]. Control and reduction the lipid level is necessary for freedom from coronary artery diseases. However, the drug therapies using niacin, clofibrate,

Adress for correspondence: Livingston Raja NR, S A Raja Pharmacy College, Rajas Nager, 627116, Vadakkangulam, India

E-mail: liviverna2016@gmail.com

Received: 12.03.2021; accepted: 28.04.2021; first published: 10.05.2021 gemfibrozil, atorvastatin, cholestyramine, cholestipol and probucol administered for the treatment of hyperlipidemia may produce an unexpected toxic effect [4]. Probucol especially was withdrawn due to its undesired side-effect of lowering HDL levels and QT interval prolongation in patients with a previous history of heart diseases (Wikipedia). Consequently, herbal rutin and its compound used for the treatment of hyperlipidemia have been approved since it has no undesirable side-effects, its use is economic and easily available [5].

Rutin is a kind of flavonol component widely distributed throughout the plant kingdom [6]. Rutin flavonoid has a number of biological effects in treating a variety of diseases, including strengthening the blood capillaries, and an antioxidative property, ant-hypertensive activity, and alphaglucosidase inhibitory activity in diabetic disords. Rutin was used in this study to investigate its hypolipidemic activity on Triton WR1339 induced hyperlipidemic rats [7].

\section{MATERIALS AND METHOD}

Drugs, chemicals and animals. Rutin (Afa Aesar), Triton WR-1339 (Sigma) suspension in 0.15 M sodium chloride. Atorvastatin from Dr. Reddy's Laboratories Ltd., and Diagnostic Kit from Merck Diagnostics India, Ltd. All chemicals and drugs used were of analytical grade. 
Mature albino Wistar of rats both genders (150-200g) were used in the study. Rats were maintained in clean, polypropylene cages and fed with pellet rat chow and water ad libitum. The research proposal was approved by the Institutional Animal Ethical Committee (IAEC) at S. A. Raja Pharmacy College, Vadakangulam, Tamilnadu, India (Proposal No. SARPC/IAEC/003/2020). IAEC follows the guidelines of CPSCEA, New Delhi, India.

Acute Toxicity activity. Acute toxicity activity was accomplished in rutin compound according to OECD guideline 423 [8]. Administration of the stepwise doses of rutin from $50 \mathrm{mg} / \mathrm{kg}, 300 \mathrm{mg} / \mathrm{kg}$, and up to the dose of $2,000 \mathrm{mg} / \mathrm{kg}$ for three animals [9]. After oral administration, the rats were observed on an hourly basis for 24 hours to assess mortality, and to detect any changes in the autonomic or behavioural responses, e.g. alertness, restlessness, grooming, touch reaction, righting reflux, salivation, urination, food intake, water intake, convulsion, writhing, skin color, corneal reflex and coma.

Anti-hyperlipidemic activity. Before starting the experiment, the rats were acclimatized to laboratory circumstances for two weeks. After that, rats were randomly prearranged into five groups, each group consisting of five rats.

Group-I: Control - Normal saline $10 \mathrm{ml} / \mathrm{kg} /$ day given by oral gavage for seven days.

Group-II: Athrogenic Control - Triton dissolved in normal saline and given in a single dose of $200 \mathrm{mg} / \mathrm{kg}$, injected intraperitonealy [9].

Group-III: The third group was given a single dose of triton administered at a dose of $200 \mathrm{mg} / \mathrm{kg}$, injected intraperitonealy. After $72 \mathrm{~h}$ of triton injection, Standard-Atorvastatin $20 \mathrm{mg}$ tablets dissolved in normal saline at a dose of $20 \mathrm{mg} / \mathrm{kg} / \mathrm{day}$, given by oral gavage for seven days.

Group-IV: the fourth group was given a single dose of triton administered at a dose of $200 \mathrm{mg} / \mathrm{kg}$, injected intraperitonealy. After $72 \mathrm{~h}$ of triton injection, Test I - rutin dissolved in normal saline at doses of $40 \mathrm{mg} / \mathrm{kg} / \mathrm{day}$, given by oral gavage for seven days.

Group-V: the fifth group was given a single dose of triton administered at a dose of $200 \mathrm{mg} / \mathrm{kg}$, injected intraperitonealy. After $72 \mathrm{~h}$ of triton injection, Test II - rutin dissolved in normal saline and the doses of $80 \mathrm{mg} / \mathrm{kg} /$ day given by oral gavage for seven days.

Rats were fed with rat chow pellets (growers' mash, Ladokun Livestock Feeds, Ibadan, Nigeria) and water ad libitum. Single dose of Triton WR 1339 at a dose of $200 \mathrm{mg} / \mathrm{kg}$ was injected intraperitonealy $72 \mathrm{~h}$ before commencement of the treatment [9]. $72 \mathrm{~h}$ after the triton injection, the entire test compound and the standard drugs were administered in each rat for seven days. After the last dose, after overnight fasting, the rats were sacrificed on the day eight and blood samples withdrawn from the retro orbital plexus into EDTA tubes. Blood samples used for the study of biochemical parameters using Randox Diagnostic's kit. Serum was estimated by total cholesterol (CHOD-PAP Method), triglycerides, LDL, VLDL and HDL cholesterol [10]. Triglycerides were determined after enzymatic hydrolysis with lipases, then spectrophotometrically (Advance Double Beam UV-VIS Spectrophotometer S-919) at the wavelength of $500 \mathrm{~nm}$ [11]. The atherogenic Index (AI) was calculated by using the following formula.

$$
\text { Atherogenic Index }=\frac{\text { Total serum triglyceride }}{\text { Total serum HDL-C }}
$$

$\%$ Protection $=\mathrm{AI}$ of control $-\mathrm{AI}$ of treated group $\times 100$ AI of control

Histopathological Investigation - Preparation of tissues for light microscopy. After administration of the last dose, the rats were sacrificed and tissue was gently dissected from the aorta and washed with normal saline $(0.9 \% \mathrm{NaCl})$ solution. The washed tissue was fixed in $10 \%$ normal saline, buffered with formalin solution, and allowed to dehydrate for one day. The dehydration process was achieved by passing the aorta tissue through an ordered series of alcohol and xylene. After completion of the processing with alcohol and xylene, the tissues were fixed in pure paraffin wax. Sections of tissues of $5 \mu \mathrm{m}$ thickness were obtained by a rotary microtome (weswox 1090a). All aorta sections were then mounted on glass slides, stained with haematoxylin and eosin. The aorta tissue sections were examined and photographed by using of Zeiss photo microscope with a Moticam 2300 digital camera 3.0 Mega pixels [12].

Statistical Analysis. The results were expressed as mean \pm SEM. The data differences between groups were analysed by one-way Analysis of Variance (ANOVA) followed by Dunnett's test.

\section{RESULTS}

Acute toxicity studies (OECD 423). The selected rutin compound did not show any behavioural changes in mortality and morbidity at $2,000 \mathrm{mg} / \mathrm{kg}$ body weight in rats. Hence, the rutin drug was considered safe for further pharmacological study of hypolipidemic activity in rats. The double dose of standard (20mg) was selected for tested material rutin (40mg/ $\mathrm{kg}, 80 \mathrm{mg} / \mathrm{kg}$ ) for examination of antihyperlipidemic activity. The parameters observed for the acute toxicity study was presented in Table 1.

Hypolipidemic activity. As expected, the results obtained showed an elevation of serum cholesterol, triglycerides, LDL and VLDL in triton WR-1339 induced hyperlipidemic control rats. This was comparable with the normal control and atorvastatin treated rats. Those animals treated with rutin showed increased HDL, decreased TC, TG, LDL and VLDL at a dose of rutin at $40 \mathrm{mg} / \mathrm{kg}, 80 \mathrm{mg} / \mathrm{kg}$. The study revealed that rutin had dose dependent activity. The results obtained were statistically significant $(\mathrm{P}<0.05)$ (Tab. 2).

Atherogenic Index. The Atherogenic Index decreased in rutin treated rats and atorvastatin treated rats, compared with control rats. The percentage protection of hyperlipidemic activity of the rutin treated groups $-40 \mathrm{mg} / \mathrm{kg}, 80 \mathrm{mg} / \mathrm{kg}$ ), were observed as $41.89 \%, 55.57 \%$, whereas in the standard 
Table 1. Common behaviour interpretations of acute toxicity study of control and rutin treated groups of rats

\begin{tabular}{|c|c|c|c|c|}
\hline S.No. & Response & Control & $2000 \mathrm{mg} / \mathrm{kg}$ & $300 \mathrm{mg} / \mathrm{kg}$ \\
\hline & Alertness & Normal & No change & No change \\
\hline & Restlessness & Usual & Usual & usual \\
\hline & Grooming & Normal & Usual & Usual \\
\hline & Touch reaction & Responded & Responded & Responded \\
\hline & Righting reflux & Natural & Natural & Natural \\
\hline & Salivation & No & No & No \\
\hline & Pupils & Common & Natural & Natural \\
\hline & Urination & Natural & Common & Natural \\
\hline & Food intake & Adequate & Adequate & Adequate \\
\hline & Water intake & Adequate & Adequate & Adequate \\
\hline & Convulsion & Nil & No & No \\
\hline & Writhing & Nil & Nil & Nil \\
\hline & Skin color & Normal & Usual & Usual \\
\hline & Corneal reflex & Usual & Usual & Usual \\
\hline & Coma & No & No & No \\
\hline & Mortality & Alive & Alive & Alive \\
\hline
\end{tabular}

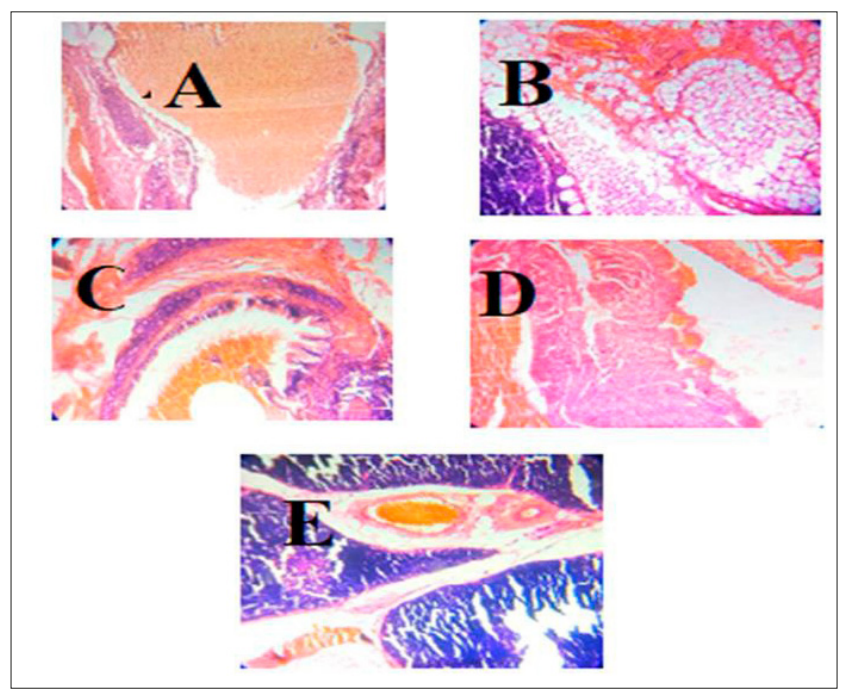

Figure I-V (A-E). Histopathological observation of aorta tissues in triton WR1339 induced hyperlipidemia in rats. Fig A denoted as Control group of aorta tissue at10X magnification. Fig B denoted as atherogenic control group of aorta tissue at10X magnification. Fig $C$ denoted as Standard drug treated group of aorta tissue at10X magnification. Fig D denoted as Rutin $(40 \mathrm{mg} / \mathrm{kg})$ treated group of aorta tissue at10X magnification and Fig E denoted as Rutin $(80 \mathrm{mg} / \mathrm{kg})$ treated group of aorta tissue at10X magnification

Table 2. Effect of rutin $(40 \mathrm{mg} / \mathrm{kg}, 80 \mathrm{mg} / \mathrm{kg})$ on serum cholesterol, triglycerides, HDL, LDL and VLDL in rats by Chem Analyser- ERBA5X Semi-Auto Analyser

\begin{tabular}{|c|c|c|c|c|c|c|}
\hline S.No & Sample Code & $\begin{array}{l}\text { Cholesterol } \\
(\mathrm{mg} / \mathrm{dl})\end{array}$ & $\begin{array}{c}\text { Triglyceride } \\
\text { (mg/dl) }\end{array}$ & $\begin{array}{c}\mathrm{HDL} \\
(\mathrm{mg} / \mathrm{dl})\end{array}$ & $\begin{array}{c}\mathrm{LDL} \\
(\mathrm{mg} / \mathrm{dl})\end{array}$ & $\begin{array}{l}\text { VLDL } \\
(\mathrm{mg} / \mathrm{dl})\end{array}$ \\
\hline 1. & Control & $137.20 \pm 1.24$ & $88.25 \pm 0.87$ & $35.69 \pm 0.23$ & $64.54 \pm 0.75$ & $18.65 \pm 0.13$ \\
\hline 3. & Standard $(20 \mathrm{mg} / \mathrm{kg})$ & $127.70 \pm 2.43$ & $68.98 \pm 1.34$ & $36.78 \pm 0.23$ & $27.88 \pm 0.15^{*}$ & $13.79 \pm 0.21$ \\
\hline 4. & Test I (40 mg/kg) & $165.85 \pm 2.56$ & $90.12 \pm 1.13$ & $32.59 \pm 0.12$ & $38.65 \pm 0.32$ & $19.02 \pm 0.34$ \\
\hline 5. & Test II (80mg/kg) & $142.80 \pm 1.45$ & $72.30 \pm 1.09$ & $34.26 \pm 0.23$ & $30.09 \pm 0.12^{*}$ & $16.86 \pm 0.32$ \\
\hline
\end{tabular}

atorvastatin treated group, protection was observe at $60.63 \%$. This is further confirmation that the rutin treated group $(40 \mathrm{mg} / \mathrm{kg}, 80 \mathrm{mg} / \mathrm{kg})$ showed a significant dose dependent protective effect of the hypolipidemic activity in rats (Tab. 3).

Table 3. The effect of atherogenic Index of rutin $(40 \mathrm{mg} / \mathrm{kg}, 80 \mathrm{mg} / \mathrm{kg})$ treated groups in rats

\begin{tabular}{|c|c|c|c|}
\hline S.No. & Treatment groups & Atherogenic Index & $\%$ Protection \\
\hline & Control & 2.47 & - \\
\hline & Induced Control & 4.75 & - \\
\hline & Standard & 1.87 & 60.63 \\
\hline & Test I (40 mg/kg) & 2.76 & 41.89 \\
\hline & Test II (80 mg/kg) & 2.11 & 55.57 \\
\hline
\end{tabular}

Histopathological evaluation. The histopathological examination was carried out in the dissected section of the aorta tissues, and revealed that aorta tissues injected with triton WR1339 exhibited a noticeable atheromatous thickening in the intima of the aorta. The atorvastatin and rutin treated rats did not exhibit any noticeable atheromatous thickening in the intima of the aorta tissues.

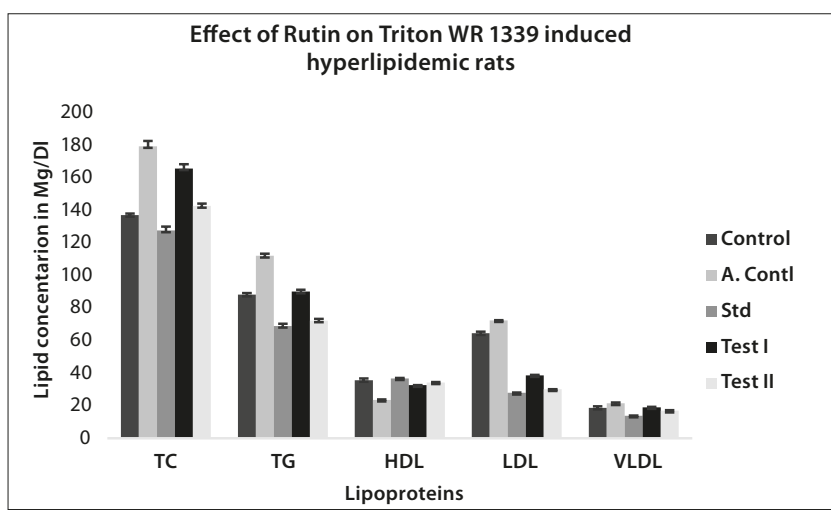

Graph 1. Denoted as the effect of rutin $(40 \mathrm{mg} / \mathrm{kg}, 80 \mathrm{mg} / \mathrm{kg})$ on serum total cholesterol, triglycerides, HDL, LDL and VLDL in hyperlipidemic rats

\section{DISCUSSION}

Cholesterol, triglycerides (TG) and high-density lipoproteins (HDL-C) are essential components of the human biological system. Cholesterol is an unsaturated alcoholic compound belonging to the steroid family which maintain the normal physiological functions of animal cells, and is a necessary element of cell membrane activity [13]. Cholesterol is important for synthesis of the adrenaline hormone and gonadal steroidal hormones. Triglycerides (TG) are fatty acid esters of glycerol which act as fat depots in humans and 
animals [14]. Cholesterol and triglycerides are non-polar lipid substances which are insoluble in water. Hence, lipoproteins act as a specific transporter for the transport the cholesterol and triglycerides in plasma [15]. Lipoproteins are classified as: 1) Chylomicron, 2) Very Low Density Lipoprotein, 3) Intermediate Density Lipoprotein (IDL), 4) Low Density Lipoprotein (LDL), 5) High-density lipoprotein (HDL). HDL-C acts as 'good' cholesterol and LDL-C acts as 'bad' cholesterol [16]. HDL is an important lipoprotein which is involved in reverse cholesterol transport, draws the excess cholesterol from cell membranes, and also inhibits the oxidation of LDL-C in the blood [17]. Clinical expressions of hyperlipoproteinaemia comprise a larger incidence of ischemic cardiovascular disease, acute pancreatitis, and yellowish deposits of lipid underneath the skin, called xanthelasmas, which usually occurs around the eyelids [18].

Currently available anti-hyperlipidemia drugs, such as statins, inhibit the HMG-CoA reductase enzyme which is responsible for the synthesis of cholesterol in liver. Atorvastatin competitively inhibits the catalytic activity of 3-OH-3-methylglutarylcoenzymeA (HMG-CoA) to a mevalonate compound which is the rate-limiting step in hepatic cholesterol synthesis. Inhibition of the HMG-CoA reductase leads to decreases in the synthesis of cholesterol in the liver, and decreases the LDL-cholesterol in the blood circulation [19].

Oral administration of the rutin flavonoid reduces the elevated lipid content in plasma. It was discovered that rutin increased the HDL cholesterol and decreased the LDL, VLDL cholesterol in plasma. This was followed by increases in the plasma LPL enzyme and Lecithin cholesterol acyltransferase enzyme (LCAT), which is an important enzyme for enhancing lipoprotein metabolism, and accelerates the maturation of high-density lipoprotein (HDL) elements [20, 21].

The current study revealed that the biphasic character of triton-induced hyperlipidemia in rat is a suitable model for understanding the mechanism of hypolipidemic drugs. Generally, lipid-lowering drugs interfere with the lipid biosynthesis pathway, lipid excretion, and the lipid metabolism pathway of the excretory phase [22]. Treatment with rutin $(40 \mathrm{mg} / \mathrm{kg}, 80 \mathrm{mg} / \mathrm{kg})$ in Triton WR1339 $(200 \mathrm{mg} / \mathrm{kg}$ BW) induced lipidemic rats exhibited a significant decrease in cholesterol, triglycerides, VLDL, LDL and an increase in HDL, compared with control group of rats. The atherogenic protection percentage of the rutin treated groups $(40 \mathrm{mg} /$ $\mathrm{kg}, 80 \mathrm{mg} / \mathrm{kg}$ ) were detected as a dose dependent protective effect at $41.89 \%, 55.57 \%$, and standard drug atorvastatin treated group was observed as $60.63 \%$ (Tab. 3), which could confirm that rutin at the $40 \mathrm{mg} / \mathrm{kg}, 80 \mathrm{mg} / \mathrm{kg}$ dose had a significant protective effect against hyperlipidemic activity in rats. LCAT combines with free cholesterol and LDL into HDL and get back to VLDL and IDL in liver [23]. Furthermore, the decreased triglyceride (TG) may be due to the enhanced effect of the endothelium lipoprotein lipase (LPL) enzyme. LPL is act by hydrolyses the triglycerides into fatty acid and also inhibits the reforming of fatty acid into triglycerides. These activities lead to a decrease in the triglycerides and cholesterol level in the blood circulation [24].

Histopathological examination revealed that the aorta tissues of the induced atherogenic control rats exhibited a marked number of fatty cells in the blood vessel. This was due to an increase in lipid peroxidation and oxidative stress in atherogenic rats, compared with normal rats [25].
Rutin and atorvastatin treated aorta tissues did not exhibit a marked number of fatty cells. The current study demonstrates evidence that rutin affects hypolipidemic activity in rats.

The results of the current study confirm that the rutin $(40 \mathrm{mg} / \mathrm{kg}, 80 \mathrm{mg} / \mathrm{kg})$ possess antihyperlipidemic effects on experimentally-induced hyperlipidemic rat models. These data was corroborating with earlier observations on Marrubium vulgare [26] and Amaranthus [27] in reducing lipid content in the experimentally-induced hyperlipidemia in rats. The antihyperlipidemic effect of the rutin is therefore partially due to the increased activity of LCAT, LPL in the cholesterol synthetic pathway.

\section{CONCLUSION}

From the results obtained from the hypolipidemic activity it was concluded that rutin treated rats $(40 \mathrm{mg} / \mathrm{kg}, 80 \mathrm{mg} / \mathrm{kg})$ exhibited an antihyperlipidemic effect. It may therefore be suggested as an antihyperlipidemic drug, or it can be used as an adjuvant therapy in the existing treatment of hypercholestraemia. Future study of the extent of plasma LPL and LCAT activity could also reveal the potential of this compound if examined extensively at molecular mechanisms level.

The result values were expressed as mean \pm SD. Statistical analysis was performed by one way ANOVA followed by Dunnet test. The obtained data were statistically significant $\left({ }^{*} \mathrm{P}<0.05\right)$.

\section{Acknowledgement}

We would like to thank Dr. Jacob Raja, Chairman of Rajas Medical Institutions, Dr. N. Balakrishnan, Principal of S A Raja of Pharmacy College for providing the facilities to carry out this work successfully.

\section{REFERENCES}

1. Niharika Verma. Introduction to hyperlipidaemia and its treatment. A Review. Int J Curr Pharm Res. 2016; 9(1): 6-14. https://doi.org/ 10.22159/ ijcpr/16616

2. Jorgensen T, Capewell S, Prescott E, Allender S, Sans S, Zdrojewski T. Population-level changes to promote cardiovascular health. Eur J Prev Cardiol. 2013; 20(3): 409-21. https://doi.org/ 10.1177/2047487312441726 3. Licto Thomas, Jagadish Vasudev Kamath. Evaluation of Antihyperlipidemic activity of Capsicum frutescens extract. Int J Curr Pharm Res. 2017; 9(3): 165-168. http://dx.doi.org/10.22159/ijcpr.2017v9i4.21289 4. Ahmed Rahma, Abu-Raghif, Hayder B, Sahib, Saba Naseer, Abbas. Anti-hyperlipidemic effect of Vitex agnus castus extracts in Mice. Int J Pharm Sci Rev Res. 2015; 35(2): 120-125.

5. Pankaj Kumar, Shailendra Sharma. Hypolipidemic Potential of Herbal Drugs Lagenaria siceraria \& Carica papaya and Cow Urine: A Review Int J Pharm Sci Rev Res. 2017; 42(2): 46: 255-264.

6. Suzuki T, Morishita T. Chapter twenty seven - Bitterness Generation, Rutin Hydrolysis, and Development of Trace Rutinosidase Variety in Tartary Buckwheat. 2016: 345-353.

7. Heba Mohamed Abdou, Mokhtar Ibrahim Yousef, Alsayeda Alsayed Newairy. Triton WR-1339-induced hyperlipidaemia, DNA fragmentation, neurotransmitters inhibition, oxidative damage, histopathological and morphometric changes: the protective role of soybean oil. The Journal of Basic and Applied Zoology. 2018; (79)51: 1-12. https://doi.org/10.1186/s41936-018-0065-z

8. Rao KS. Acute Oral Toxicity. BEMS Reports. 2018; 4(2):39-41. https:// doi.org/ 10.5530/bems.4.2.10.

9. Mukesh S, Sikarwar Patil MB. Antihyperlipidemic activity of Salacia chinensis root extracts in triton-induced and atherogenic diet-induced hyperlipidemic rats. Indian J Pharmacol. 2012; 44(1): 88-92. doi: 10.4103/0253-7613.91875 
10. Sikarwar MS, Mrityunjaya B. Patil. Antihyperlipidemic Activity of Pongamia pinnata Leaf Extracts. Turk J Pharm Sci. 2014; 11(3): 329-338.

11. Swati Penumarthy, Gautami S. Penmetsa, Satheesh Mannem. Assessment of serum levels of triglycerides, total cholesterol, highdensity lipoprotein cholesterol, and low-density lipoprotein cholesterol in periodontitis patients J Indian Soc Periodontol. 2013; 17(1): 30-35. https://doi.org/10.4103/0972-124X.107471

12. Shraideh Ziad, Al-Awaida Wajdy, Badran Darwish. Effects of cigarette smoking on histology of trachea and lungs of albino rat. Res Opin Anim Vet Sci. 2013; 3(10): 356-362.

13. Alexandros Tsoupras, Ronan Lordan, Ioannis Zabetakis. Inflammation, not Cholesterol, Is a Cause of Chronic Disease. Nutrients. 2018; 10(5): 1-38. https://doi.org/10.3390/nu10050604

14. Obeagu EI. Lipoprotein implication and Laboratory estimation. Int J Adv Res Biol Sci. 2016; 3(6): 123-130. http://s-o-i.org/1.15/ijarbs-2016-3-6-16

15. Antonio Blanco, Gustavo Blanco, in Medical Biochemistry. 1st Edition. Argentina. 2017.

16. Kieran F. Docherty, Sandosh Padmanabhan. Handbook of Pharmacogenomics and Stratified Medicine. Institute of Cardiovascular and Medical Sciences, University of Glasgow, UK. $1^{\text {st }}$ edition. 2014.

17. Mireille Ouimet, Tessa J. Barrett, Edward A. HDL and Reverse Cholesterol Transport Basic Mechanisms and Their Roles in Vascular Health and Disease. Circulation Research. 2019; 124(10): 1505-1518. http//doi.org/10.1161/CIRCRESAHA.119.312617

18. Manni A, Quarde A. Signs in Disorders of Lipid Metabolism and Obesity. In Endocrine Pathophysiology. Springer, Cham. 2020: 151-170. https://doi.org/10.1007/978-3-030-49872-6_7

19. Huanbiao MO, Rayna Jeter, Andrea Bachmann, Sophie T. Yount, Chwan-Li Shen, Hoda Yeganehjoo. The Potential of Isoprenoids in Adjuvant Cancer Therapy to Reduce Adverse Effects of Statins. Front. Pharmacol. 2019; 9(1515): 1-19. http//doi.org/ 10.3389/fphar.2018.01515
20. Agrawal S, Zaritsky J, Fornoni A. Dyslipidaemia in nephrotic syndrome: mechanisms and treatment. Nat Rev Nephrol. 2018; 14: 57-70. https:// doi.org/10.1038/nrneph.2017.155

21. Heqian Kuang, Fang Yang, Yan Zhang, Tiannan Wang, Guoxun Chen. The Impact of Egg Nutrient Composition and its Consumption on Cholesterol Homeostasis. Cholesterol. 2018: 1-22. https://doi. org $/ 10.1155 / 2018 / 6303810$

22. Ghassan F. Shattat. A Review Article on Hyperlipidaemia: Types, Treatments and New Drug Targets. Biomed \& Pharmacol J. 2014; 7(2): 399-409. https://dx.doi.org/10.13005/bpj/504

23. Sandra Kunnen, Miranda Van Eck. Lecithin: cholesterol acyltransferase: old friend or foe in atherosclerosis? J Lipid Res. 2012; 53(9): 1783-1799. https://doi.org/10.1194/jlr.R024513

24. Sheneni VD, Shaibu IE, Okpe JM. In-vivo biological effect of Carica papaya leaf extracts on $\mathrm{P}-407$ induced hyperlipidemic Wistar rats. MOJ Food Process Technol. 2018; 6(4): 409-412. https://doi.org/10.15406/ mojfpt.2018.06.00196

25. Titin Andri, Wihastuti, Djanggan Sargowo, Teuku Heriansyah, Yasmin Eka Aziza, Dyah Puspitarini, Amalina Nur Iwana, Lucky Astrida Evitasari. The reduction of aorta histopathological images through inhibition of reactive oxygen species formation in hypercholesterolemia rattus norvegicus treated with polysaccharide peptide of Ganoderma lucidum. Iran J Basic Med Sci. 2015; 18(5): 514-519. PMC4475661

26. Abeer Y, IbrahimSaber F Hendawy, Ahmed AA, Elsaye, Elsayed A Omer. Evaluation of hypolipidemic Marrubium vulgare effect in Triton WR-1339-induced hyperlipidaemia in mice. Asian Pacific Journal of Tropical Medicine. 2016; 9(5): 453-459. https://doi.org/10.1016/j. apjtm.2016.03.038

27. Yan Zhang, Liying Wu, Zhongsu Ma, Jia Cheng, Jingbo Liu. AntiDiabetic, Anti-Oxidant and Anti-Hyperlipidemic Activities of Flavonoids from Corn Silk on STZ-Induced Diabetic Mice. Molecules. 2016; 21(7): 1-12. https://doi.org/doi: 10.3390/molecules21010007 